\title{
La isla de Calibán
}

Julio Ortega

Brown University

La tempestad de William Shakespeare es una de sus obras más estudiadas en relación a la empresa colonial europea en las Américas y la construcción de una imagen del hombre americano. En los últimos 20 años, la crítica "post-colonial" ha visto en ella la demostración de la mirada central (a través de Próspero, representante de los poderes político y mágico) que convierte a Calibán (el habitante de la isla caribeña) en un monstruo, que es además siervo, y criatura desprovista de juicio moral. A esa versión del "hombre natural" este estudio opone una interpretación basada en el "buen salvaje", favorecida por Montaigne y no ajena a Shakespeare. Según esta versión, Calibán no es sólo un "monstruo" sino también una criatura humana que, gracias al lenguaje, no sólo aprende "a maldecir" sino a nombrar la abundancia de su isla nativa.

Palabras Clave: Shakespeare, Calibán, Montaigne, Antonio de Esteva, abundancia, hombre natural, buen salvaje, colonial, post-colonial, Stephen Grinbaltt, Roberto Fernández Retamar, Renan, Aime Cesar.

Shakespeare's Tempest has been discussed in relation to the European colonial adventure in the New World as a representation of the native as "natural man." In the last two decades, the "post-colonial" reading of Tempest questions the central gaze (Prospero represents political and magic powers) that makes of Caliban a monster, an slave deprived of moral judgement. This article confronts that reading with the notion that Caliban is also a human creature that, thanks to language not only learns "to curse" but also to name, to recognize the abundance of nature in his native island. It moves, thus, from the "natural man" to the "good savage", a version favored by Montaigne and not ignored by Shakespeare.

KEYwords: Shakespeare, Calibán, Montaigne, Antonio de Esteva, abundance, natural man, good savage, colonial, post-colonial, Stephen Grinbaltt, Roberto Fernández Retamar, Renan, Aime Cesar.

Calibán, cuyo nombre es anagrama de caníbal y, por lo tanto, se remonta a Caribe, es en The Tempest (1612-1613), la última obra de Shakespeare, una intrigante representación del hombre del Nuevo Mundo. ${ }^{1}$ Proviene de distintas fuentes literarias y legendarias pero, sobre todo, de la historia colonial europea, de la mezcla de aventura y de asombro asociada a la exploración de las colonias americanas. Su figura corresponde a la noción del "hombre natural", que entiende al colonizado como primitivo,

1 The Tempest. The New Folger Library. Edited by Barbara A. Mowat and Paul Werstine. Washington Square Press, 1994; esta edición dedica atención a la lectura postcolonial de la obra. Hemos consultado así mismo Frank Kerdmode (ed.): The Tempest. The Arden Shakespeare. London, Methuren, 1954; y George Lymann (ed.): The Tempest. The Kittredge Shakespeare. Kittredge, revised by Irving Ribner. Xerox College Publishing, 1967. 
desprovisto de lenguaje y, por tanto, de moral. Desde Aristóteles, la noción del salvaje dominado por su condición natural justifica la esclavitud y sostiene el poder rector del amo. ${ }^{2}$ En la edición Folio de las obras de Shakespeare, donde The Tempest inicia el tomo, el reparto de personajes califica a Calibán de "un esclavo salvaje y deforme". Su maldad innata, sin embargo, es inocente, desprovista de conciencia y de culpa; lo cual refrenda la función del amo, cuya autoridad asegura el proceso de humanización del pequeño monstruo.

Próspero, Duque de Milán, despojado del poder por su propio hermano, ha tomado la isla de Calibán y la ha transformado, con su magia, en un lugar encantado. Retirado del mundo con su hija Miranda, servido por Ariel y Calibán, vive dedicado a sus libros, al poder del lenguaje con que controla la naturaleza. El lenguaje es aquí la forma resolutiva del conflicto: transfigura al mundo natural, norma la servidumbre del nativo y restablece el orden político. La naturaleza americana se expresa a través de los prodigios de su abundancia, pero sólo se hace inteligible en su función mayor: sostener el orden legítimo y la ciudad de los hombres. La colonización, en último término, es una escenificación de los poderes del lenguaje alegórico, de su magia literal y de su lectura política. La colonización construye una otredad europea donde la legitimidad se reconoce en un espejo más lúcido: la isla de Calibán es el espejo de la ciudad estado-italiana en esta parábola inglesa. Al final, se trata de la lección clásica sobre el buen gobierno y el mejor gobernante que restituyen el orden fecundo del cosmos. Esta isla del discurso renacentista es, por eso, el lugar redimido del hijo de la naturaleza, Calibán, quien se transforma en hijo del lenguaje. Aprender a hablar será para él aprender a reconocer y enumerar su propio mundo para hacerlo suyo en el discurso.

Shakespeare pudo haber tomado esta fábula del capítulo cuarto de Las noches de invierno (1609), de Antonio de Eslava, donde se cuenta la historia de Dárdano, rey de Bulgaria, despojado por Nicéforo, rey de Grecia. Dárdano es además nigromante y tiene una hija, Serafina, con la que decide abandonar el mundo y refugiarse en un palacio construido en el fondo del mar. ${ }^{3}$ Probablemente la historia misma se remonta a una fuente anterior,

2 Anthony Pagden ha estudiado el traslado al Nuevo Mundo de estas imágenes e ideas en su The Fall of Natural Man, Cambridge University Press, 1982. Un amplio repaso sobre las ideas europeas en torno a América, de Colón a Hegel, viene en Gerbi, Antonello: The Dispute of the New World, University of Pittsburgh Press, 1973.

3 Eslava, Antonio: Noches de invierno, Ed. de Julia Barella Vigal, Departamento de Educación y Cultura del Gobierno de Navarra, Pamplona, 1986. 
italiana. En cualquier caso, los paralelos de la pieza de teatro con esa fábula española del poder, donde se enfrentan el mago órfico y el político maquiavélico, subrayan el común presente conflictivo del debate político. A comienzos del siglo XVII ese debate está animado por la rica naturaleza del Nuevo Mundo, la extrañeza de sus habitantes sin relato y la necesidad de que las colonias sean legítimas plantaciones, reducciones o encomiendas, centros de reproducción de bienes, tanto pragmáticos como simbólicos, en el nuevo mapa imperial. Más allá de las coincidencias episódicas, la fábula y la pieza coinciden en revelar una correspondencia entre la ruptura del orden político (la usurpación del gobernante legítimo) y la fractura del orden natural (la magia como metáfora sobrenatural). En la fábula ejemplar de Eslava, esta "noche de invierno" es un cuento sobre los límites de la naturaleza, la noción de lo natural y el poder del hombre sabio (del sujeto virtuoso postulado por Aristóteles). El mago le explica a su hija que "todo cuanto hay en este inconstante mundo es a modo de una continua guerra"; tanto las fuerzas cósmicas como las humanas están regidas por movimientos contrarios, donde "los adversos elementos pelean entre sî". Y termina diciéndole: "Pues, si esto es en las criaturas insensibles y inanimadas, ¿qué será en las sensibles y racionales? Y así...te juro por el eterno Caos de no hacer de hoy más mi habitación entre los hombres...”. Aunque se reitera aquí el tópico literario, este juramento a nombre de la autoridad de un Caos eterno, hecho por un mago sabio y bueno, es el exacto revés de otra imagen, contraria y simétrica, la del "mágico palacio" dentro del mar, construido por el arte y preservado por el encantamiento. Si la naturaleza (el mundo y los hombres) está dominada por la discordia desigual de fuerzas y pasiones, la magia es el arte sobrenatural, capaz de imitar el orden superior de la filosofía moral. En el diálogo que sigue al cuento, Eslava comenta extensamente la magia, y consigna una imagen híbrida, que preanuncia a Calibán, percibido también como un pez monstruoso:

Teodoro Gaza, que fue hombre docto y ha poco tiempo que murió, vio que, habiendo habido en el mar grande tormenta, con sus combates arrojó en tierra en una playa mucha cantidad de varios peces, y que entre ellos había una nereida que tenía forma y rostro de mujer hasta la cintura, y que de allí para abajo fenecía en una cosa a manera de anguila, que es de la suerte misma que se pintan las sirenas o nereidas.

En esta naturaleza desconocida y discorde, la tempestad suscita tanto el desorden de las formas como la hibridez de los sujetos ambiguos, que son verdaderos enigmas donde cabe leer la íntima irracionalidad de lo natural. La naturaleza está aquí librada a su suerte combinatoria, y es materia 
ella misma del orden suplementario y alterno de la magia. El desencanto mundano suscita, por tanto, el encantamiento secreto. Sólo que la naturaleza humana termina imponiéndose con su ciclo de regeneraciones cósmicas: Serafina demanda un compañero y su padre le encuentra al príncipe que recobrará el orden político, la legitimidad del poder sabio. Un teatro cósmico y político concluye así en romance familiar, a favor del orden ganado a una naturaleza fecunda en enigmas y asombro.

Al situar The Tempest en una isla del Mediterráneo, Shakespeare huye a la vez de la historia (Bulgaria) como del mito (el palacio mágico dentro del mar) para afincar en su propio terreno, el teatro de lo sobrenatural y el escenario de la política. Buscó hacer una obra más propia del romance que de la historia. La isla se levanta como una trampa encantada, y por medio de sus poderes mágicos Próspero logrará que la tempestad le traiga a su hermano usurpador. El orden político se restablece, gracias a la restitución y el linaje. Y el caos ameno del artificio no corresponde ya al Caos eterno de las fuerzas contrarias, sino a la estrategia restauradora de Próspero. En la pieza, el caos y la magia son principios escénicos, instrumentos del espectáculo. Ese despliegue de artificio, capaz de reemplazar a la naturaleza, tiene en la fecundidad y la mutación su fuerza desencadenante. La isla es un lugar de la abundancia, pero también un escenario del cambio que anuncia lo moderno. Esa doble valencia (abundancia, cambio) son de signo caribeño. Calibán, hijo de un íncubo y una bruja, producto del pecado original de la naturaleza salvaje, es en verdad el primer personaje o la primera máscara del sujeto colonial moderno. Esto es, Calibán es una representación del Otro, primario y brutal, incapaz todavía de responsabilidad moral, pero capaz de aprender y responder, de rehacerse entre los discursos humanistas que profetizan la modernidad y prometen la gracia. Aunque más que la representación de un aborigen caribeño, es una tentativa de imagen, una imagen en crisis: su origen, su naturaleza, su forma no son representables, ni siquiera su descripción y mucho menos su designación están del todo fijadas. Es un personaje que pone en tensión la posibilidad de dar cuenta de su diferencia radical.

Pero no sólo el nombre de Calibán y la figura de "salvaje" remiten al Nuevo Mundo. También, el asombro de una geografía fantástica, descubierta por los relatos del viaje transatlántico. The Tempest, en efecto, está inspirada en los populares recuentos de un famoso naufragio en la isla de Bermuda. En julio de 1609 la flota que llevaba al nuevo gobernador inglés de las colonias norteamericanas fue dispersada por una tormenta; la nave 
del gobernador terminó naufragando en las Bermudas, donde los tripulantes pasaron cosa de un año, supuestamente en un estado de deleite paradisíaco. Los relatos de esa peripecia cautivaron a los lectores ingleses. Shakespeare, sin duda, leyó alguna de esas relaciones y cartas, y utilizó libremente si no la historia sí su resonancia exótica; quizá sobre todo la experiencia de la novedad, extrañeza y curiosidad ante el Nuevo Mundo, las colonias remotas y las islas ignotas. Es este contexto de la actualidad colonial lo que hace más verosímil la presencia de un nativo isleño como Calibán. Aun si la fábula misma es arcaica y su genealogía el romance italiano, esta actualidad colonial le confiere a la obra su inserción en el espacio insondable de la aventura americana. ${ }^{4}$

En cualquier caso, para nuestra lectura es más importante que esta refundición de fuentes diversas, la interrogación que el enigma de Calibán impone a los registros de la mirada colonial. Por lo pronto, parece evidente que su índole de "hombre natural", el lado irredento de su ser primario, está en tensión con su humanización, el lado redimible de su condición de "noble salvaje". Miranda le ha enseñado a hablar, y su capacidad de aprender es también su conciencia del poder del lenguaje. Su respuesta lleva la fuerza de la significación del colonizado que se asume como sujeto del lenguaje del Otro, siendo él mismo un Otro del lenguaje. Esto es, se construye como el saber verbal de una identidad que se afirma gracias a las palabras:

You taught me language, and my profit on 't

Is I know how to curse.

El lenguaje, en efecto, le ha dado la subjetividad contradictoria. Pero no sólo porque el lenguaje le haya enseñado a maldecir sino porque maldecir es la ganancia que él reconoce de haber aprendido a hablar. Es "mi ganancia", dice, porque esa es la parte sólo suya, la prueba de su libertad interior en el saber y el reconocer. Maldecir es la metáfora de un habla pro-

4 Los varios relatos del famoso naufragio fueron populares en tiempos de Shakespeare. Lo cuenta así Lyman Kittredge: "On June 2, 1609, a fleet of seven ships and two small vessels sailed from Plymouth to Virginia. The flagship, the Sea Adventure, carried the new Governor (Sir Thomas Gates), the Admiral (Sir George Somers), and Captain Christopher Newport. On July 24 a terrible storm scattered the fleet. It arrived at Jamestown in August, but the Sea Adventure was missing. She had run ashore on the Bermudas in July 28, but without loss of life. Gates, Somers, and the rest — some 150 in allremained on the island for about nine months... In 1610, soon after their arrival [back to England], three narratives of these adventures were published...More important, however, is a long letter from William Strachey, another of Somer's companions...The resemblance between Strachey's letter and The Tempest can hardly be accidental". Kitleridge (ed.): The Tempest..., Introduction, págs. XII-XIII. 
pia, de una apropiación consciente, sarcástica y rebajadora. Por eso, de inmediato habla en un aparte, reconociendo el poder de su amo, y la necesidad de controlar la escena de habla: "I must obey", se dice a sí mismo, temeroso del poder del mago. El lenguaje aprendido le permite conocer sus límites, afirmar su cuerpo, representar su papel. Pero también le permite actuar la identidad de nativo que le atribuyen los otros, incluso jugar con su nombre y su reputación de malvado. Ya en su primera aparición Miranda le declara aborrecimiento y piedad, porque el esclavo ha intentado violarla, demostrando su salvajismo. Ella lo increpa no sin crudeza, y él se afirma en su identidad contradictoria. Pero su intento criminal no debe ser tan grande porque lo ha cometido un hombre sin malicia, instintivo y brutal, pero también grotesco y hasta cómico. Su respuesta es a la vez villana y festiva: él y Miranda podrían, dice, haber poblado la isla de Calibanes.

Pero Calibán, como sus remotos parientes los indios de las Antillas, no se debe solamente a una representación arcaica, la del "hombre natural" o salvaje. Su configuración en manos de Shakespeare lleva también la marca de otra representación, la del habitante arcádico, la del nativo del paraíso. Su hibridismo es físico (un monstruo, después de todo, hecho de retazos discursivos) y por ello, teatral: una metáfora de la extrañeza caribeña. Esto es, una pesadilla europea, cuyo trasfondo revela tanto la mala conciencia colonial como su justificación retórica. Pero ese hibridismo es también la incongruencia, la tensión de dos modelos de representar al Otro: como salvaje y, por tanto, esclavo; y como hijo de la abundancia y, por tanto, redimible. Por lo primero, Calibán es excluido del orden y condenado a padecerlo; por lo segundo, su maldad es la de un niño brutal: su conducta es perdonada por Próspero, y él mismo anuncia al final que ha aprendido la lección: será más sabio, y buscará la gracia, dice. Su nueva conciencia lo convierte ya en un ciudadano.

Otras resonancias animan la hibridez del Calibán americano. Al comienzo del primer acto, anuncia:

This island's mine, by Sycorax my mother,

Which thou tak'st from me. When thou cam'st first,

Thou strok'st me and made much of me, wouldst give me

Water with berries in't, and teach me how

To name the bigger light and how the less,

That burn by day and night. And then I loved thee.

And showed thee all the qualities o'th'isle,

The fresh springs, brine pits, barren place and fertile.

$(1.2,396-405)$ 
Esta declaración señala la relación amo/esclavo como central a la forma del poder colonial. Señala también algo menos obvio y más importante: el desgarramiento del nativo, colonizado por el lenguaje, y hasta por la fe adquirida (ha aprendido, nos dice, a nombrar las estrellas, referencia al Génesis 1.16); pero ese aprendizaje es a costa de su heredad y pertenencia. $\mathrm{Su}$ identidad es, ahora, ese despojo. Este gesto tiene una poderosa resonancia en la América del siglo XVII y alude al discurso de los mestizos, esos primeros habitantes de la hibridez colonial. Como Calibán, los mestizos desafían a la autoridad colonial al declarar que la tierra es suya por doble filiación: la heredaron de sus madres y la ganaron por sus padres. Propiedad y conquista, herencia y ganancia se suma en ellos, que son hijos de la violencia fundadora pero también padres del nuevo discurso americano, el que suma las discordias del origen y las opciones del porvenir. ${ }^{5}$

Se trata, además, de una tierra privilegiada: la isla de Calibán es un emblema de la fertilidad. Próspero la ha transformado en un escenario mágico, donde sus esclavos (Ariel, Calibán) le sirven no sin agonía; pero la isla sigue siendo un escenario de la abundancia, de la fecundidad. Hasta la cómica rebelión que Calibán prepara con sus compinches está hecha a nombre de ese emblema: "I'll show thee every fertile inch o'th'island" (2.2, 154); y en seguida: "I'll show thee the best springs. I'll pluck thee berries. I'll fish for thee and get thee wood enough" $(2.2,166-167)$. La escena es cómica porque los conspiradores están borrachos, pero la abundancia es un motivo que está detrás de la rebelión contra el poder de Próspero; y anima también la servidumbre de Calibán ante los pobres diablos que confunde con señores. La abundancia es una causa primera, a pesar de la confusión de Calibán, y es también la fuente discursiva que promueve un nuevo orden posible. El noble Gonzalo ("an honest old councillor") ha confirmado el emblema, cuando glosando a Montaigne, exclama:

\footnotetext{
I' th' commonwealth I would by contraries

Execute all things; for no kind of traffic

Would I admit; no name of magistrate;

Letters should not be known; riches, poverty,

And use of service, none; contract, succession,

Bourn, bound of land, tilth, vineyard, none;

No use of metal, corn, or wine, or oil;
}

5 La noción de que los mestizos son doblemente dueños de la tierra americana, porque además de ser heredad materna fue conquista paterna, es argumento esgrimido como desafío. Ese desafío era considerado, en los reportes oficiosos de la vida colonial, como prueba de que los mestizos eran díscolos y peligrosos. 


\section{JULIO ORTEGA}

No occupation; all men idle, all

And women too, but innocent and pure;

No sovereignty.

(...)

All things in common nature should produce

Without sweat or endeavor; treason, felony,

Sword, pike, knife, gun, or need of any engine

Would I not have; but nature should bring forth

Of its own kind all foison, all abundance,

To feed my innocent people.

$(2.2,162-180)$

La fecundidad natural se reitera al final (foison, abundance) como bien común, alimento colectivo y libre. Esta escena emblemática (que el consejero Gonzalo deriva del tópico de la Edad de Oro) muestra la complementariedad simbólica que subyace en el sistema de representaciones shakespereano: en el mundo nativo (de fecundidad natural) se trama el de las Edades (de estirpe clásica), que es actualizado como modelo político del bienestar común, la justicia ideal y la propiedad compartida. En la escena paradisíaca caribeña se levanta el escenario de una abundancia convertida en utopía filosófica y social. El contrato colonial del amo y el siervo (la ética del poder civilizatorio proclamada por Próspero ante Ariel y Calibán) es contrastada aquí por la estética de una eticidad (la noción del buen gobierno igualitario). Se trata de un contraste no por especulativo menos poderoso, no por nostálgico menos articulado a la inquieta novedad (otredad) de las islas del Caribe.

No es casual, por lo mismo, que estas postulaciones utópicas de Gonzalo se sustenten en el ensayo que Montaigne dedicó a los caníbales. Se lee allí:

Bien podemos por lo tanto llamarlos bárbaros si consideramos las normas de la razón mas no si nos consideramos a nosotros mismos que los superamos en toda clase de barbarie. Su guerra es absolutamente noble y generosa, y tiene tanta justificación y belleza como esta enfermedad humana puede contener; para ellos no tiene otro fundamento que el sólo celo por el valor. No combaten para conquistar nuevas tierras pues gozan todavía de esa felicidad natural que les abastece de todo lo necesario sin trabajo ni esfuerzo y en abundancia tal que no necesitan para nada aumentar sus límites. Aun están en ese mundo feliz en que sólo necesitan lo que sus necesidades naturales exigen; todo lo demás es para ellos superfluo. Generalmente se llaman unos a otros, los que son de la misma edad, hermanos; hijos, a los que están por debajo; y los ancianos son padres para todos los demás. ${ }^{6}$

6 Montaigne, Michel de: "De los Caníbales". Ensayos, I, cap. XXXI. Ed. de Dolores Picazo y Almudena Montojo. Cátedra, Madrid, 1985, pág. 273. 
Este exceso de la abundancia es tanto una felicidad social como una estética de la ética comunal. Se trata de una escena a la vez filosófica y crítica, que diseña el bien común y que cuestiona la actualidad provincial, desligada. Los americanos se le aparecen "aún muy cerca de la inocencia original (268)". Esto es, todavía no conquistados por la culpa histórica, por la interpretación ejercida por los poderes, que condena a esas naciones a la servidumbre. La abundancia nativa es la actualidad de la Edad de Oro, pero la dominación europea es la adulteración ("Rígense todavía según las leyes naturales, apenas adulteradas por las nuestras", 268). Montaigne dramatiza su alegato por el Nuevo Mundo con cierto escepticismo melancólico. Su visión política no es menos contrastante: el emblema de una abundancia adulterada sugiere que el relativismo de las interpretaciones pertenece al pensamiento crítico moderno, pero que la suerte de las representaciones se decide en las manos más poderosas. ${ }^{7}$

Stephen J. Greenblatt cree que Shakespeare asume la perspectiva condenatoria del Hombre Salvaje, la que incluso exagera en la figura de Calibán; por ello, concluye que éste es cualquier cosa salvo un Noble Salvaje. Y, sin embargo, el "hombre natural" que, efectivamente, late en la figura de Calibán se desdobla en la figura del salvaje inocente. ${ }^{8}$ La primera imagen lo condena a la sujeción contractual del amo civilizador; la segunda, refuta el poder del amo con su utopismo colectivista.

Afirma también Greenblatt:

The Tempest utterly rejects the uniformitarian view of the human race, the view that would later triumph in the Enlightenment and prevail in the West to this day. All men, the play seems to suggest, are not alike; strip away the adornments of culture and you will not reach a single human essence.

Pero, cabe argüir, esa conclusión sólo puede ilustrar una filosofía moral, que diferencia a los sujetos históricos frente al poder y la política. En cambio, las diferencias entre Calibán, los criados, los cortesanos, los usurpadores y el mago son grados de representación entre la naturaleza primaria y la sociedad política legítima; el eje de esa representación es con-

7 Dice también Montaigne: "Esas naciones parécenme por lo tanto bárbaras porque la mente humana las ha moldeado muy poco y están aún muy cerca de la inocencia original. Rígense todavía según las leyes naturales, apenas adulteradas por las nuestras; mas en tal pureza que me apena a veces que no hayan sido conocidas preferiblemente en la época en que había hombres que habrían sabido juzgarlas mejor que nosotros". Montaigne: Caníbales..., pág. 268.

8 Greenblatt, Stephan J.: "Learning to Curse: Aspects of Linguistic Colonialism in the Sixteenth Century". Learning to Curse, Essays in Early Modern Culture, 1992. 
trastante: gira entre un retiro a las fuentes naturales (la isla de la abundancia y lo sobrenatural) y un retorno a la ciudad recobrada por la legitimidad y el buen gobierno. Se trata así de un proceso de humanización que revela una común cualidad humana. Por eso, el bien de la abundancia se refleja mejor en el bien común del buen gobierno.

Calibán y el Caribe están en el centro de ese debate, no resuelto por Shakespeare; más bien, transferido por la pieza a una dimensión de magia benéfica -metáfora humanista, que promedia con su fantasía el asombro inmanente de lo natural. Si la naturaleza es pródiga en bienes, ¿cómo entender que sea avara en belleza humana y que se complazca en contradecir la materialidad benéfica insular con la patética hibridez del hijo de la bruja y del íncubo? (Hijo americano, en efecto, de la negatividad del margen europeo). Quizá el problema sea contrario: hay una esencia humana universal, sólo que no está normada del todo. Como lo entendió Montaigne, es una naturaleza en formación, quizá horrible a nuestros modos de representar y verificar, pero libre de las deformaciones que acarrea la adulteración (del sentido, de la moral, del bien común) impuesta por el poder (colonial, ideológico, cultural). Al final, esa "raza humana" es una metáfora de la humanidad en desenvolvimiento a través de los hombres: la cultura es la forma de su "esencia", el sistema de sus escenarios de reflexión y actuación. Por eso, no es casual que en The Tempest Calibán encuentre a sus semejantes en los siervos; y que su "salvajismo" sea menos culpable que la violencia política y moral que representa Antonio, hermano de Próspero, "the usurping Duke of Milan". Desheredado de su isla original, Calibán hereda los fragmentos de un discurso que lo construyen y disputan. Por eso maldice, porque contradecir esos discursos es el primer gesto para apoderarse de ellos. Su inocencia no tiene destino social: no puede todavía articular los discursos como su nuevo instrumento para, a su turno, reconstruir su isla perdida.

En buena cuenta, Shakespeare encontró en Calibán al sujeto paradójico (hecho de inocencia, visto desde la ironía) que podría habitar el paraíso ameno entrevisto por Montaigne. Sabemos que The Tempest aprovecha el capítulo sobre los Caníbales, donde se lee:

Tan salvajes son como los frutos a los que llamamos salvajes por haberlos producido la naturaleza por sí misma y en su normal evolución: cuando en verdad, mejor haríamos en llamar salvajes a los que hemos alterado con nuestras artes, desviándolos del orden común. En aquellos están vivas y vigorosas las auténticas cualidades y propiedades más útiles y naturales, las cuales en cambio, hemos envilecido en éstos, adap- 
tándolas simplemente al placer de nuestro gusto corrompido. Y así, sin embargo, el sabor y la suavidad de distintos frutos de aquellas zonas sin cultivo, resultan ser excelentes para nuestro gusto y mejores que los nuestros. No hay razón para que lo artificial supere a nuestra grande y poderosa madre naturaleza. Hemos recargado tanto la belleza y riqueza de sus obras, con nuestros inventos, que la hemos asfixiado por completo. Y aún así, allá donde reluce su pureza, hemos de avergonzarnos extraordinariamente de nuestras frívolas y vanas empresas.

En The Tempest, la figura de Calibán y el tópico de la abundancia parecen deber a las reflexiones de Montaigne si no la parte más escénica del juego especular, sí la contrastante interrogación del juego reflexivo. Lo que Montaigne llama la "normal evolución" de la naturaleza, es el proceso que Shakespeare desencadena en escena para mostrarlo desde las diversas mascaradas y desenmascaramientos que construyen la aventura de conocer y de imaginar otros mundos y otros hombres. De vuelta de esas islas, el conocimiento del otro deduce también el nuevo conocimiento del yo: un sujeto distinto se proyecta en esa disyunción, alteridad y suma. La misma isla remite al archivo mediterráneo, pero proyecta la actualidad histórica americana. La abundancia en que se expresa la naturaleza permite concluir que la incongruencia de Calibán se resuelve como una suma híbrida, desigual pero en despliegue. Por un lado, Calibán es la suma europea de leyendas, versiones y percepciones de diversa fuente y sanción; pero, por otro, su hibridez es ya del Nuevo Mundo: dejará de ser un monstruo de la leyenda para ser el primer hombre de su isla. Al final, Calibán preside un lenguaje que evoluciona del escenario perdido a la escena ocupada.

Las nuevas lecturas de la obra han ido más allá del lugar común tradicional sobre el romance como género dominante; y exceden ahora la sobredeterminada noción de que la pieza confirma la ideología colonial de su tiempo. Por un lado, el mapa de los contextos imbricados (la empresa de dominio colonial, la exploración marítima, el debate sobre el hombre americano, el Viejo Mundo y el Nuevo Mundo paralelos); y por otro lado, la serie paralela de los discursos (lo natural y lo sobrenatural, el artificio y la política, el esclavo y el amo, el hombre natural y el buen salvaje), han hecho evidente que cada declaración en la obra tiene su contraparte y, a veces, su refutación. A tal punto que la obra está animada por una "ambivalencia radical". La serie de los contrastes incluye figuras opuestas y lenguajes alternos, confronta la ley natural y el arte sobrenatural, lo real y lo aparencial, lo dado y lo construido, lo literal y lo hiperbólico; y se nos aparece como una dinámica escenificada de ejemplos 
figurados para lección y prueba. Estas tensiones, inmediatas o mediadas, evocan la imagen del Caos glosada por Eslava, así como el tópico presocrático de las fuerzas en discordia. Esta "tempestad", después de todo, no es sólo la de los vientos contrarios sino que también es metáfora de las transformaciones, potencialidad de los procesos, y emblema de los objetos nuevos, orillas recientes y voces otras. En último término, el juego de la significación hace de las series y las alegorías otra "mascarada". Todo intento de fijar el lenguaje aparece contradicho por la potencialidad que el mismo lenguaje tiene para des-representar su papel nominativo, normativo. Es por eso que ni siquiera el lenguaje de Próspero representa a la obra, es sólo uno de sus ejes. Y hasta la filosofía natural que despliega la elocuencia de Gonzalo (el intelectual de la pieza, aquél que quiere darle un discurso a lo nuevo a su demanda de articulación) es refutada por el sarcasmo mundano de quienes aducen, contra su regusto utopista, la crudeza de un medio más hostil que paradisíaco. Todo ello sugiere la ambigüedad como sustitución permanente de una realidad fluida y cambiante. Aun si el desarrollo de la pieza es una fábula esquemática, su despliegue de mascarada tiene un regusto barroco. Esto es, si ningún término es necesariamente el promedio de lo natural o lo real, quiere decir que sólo tenemos estos discursos des-representados, que potencian la experiencia humana en un medio fecundo, y que designan como humanidad a un horizonte de virtualidad no fijada. Esa celebración de la potencialidad del lenguaje no es menos crítica. En verdad, es la des-alienación del lenguaje nominal, restrictivo y escindido, lo que permite en la pieza el canje, la máscara y la reinscripción. Ni siquiera Miranda, con ser más literal, habla un solo lenguaje, y más bien parece adelantar un nuevo sujeto, aquel que viene de Europa, pasa por las islas (Encantadas o Del diablo, según la escena) y da la vuelta sobre sí misma, capaz de reemplazar a su padre cuando llama a su antiguo origen "a new brave world". América, en efecto, ha hecho más nuevo al Viejo Mundo. Se trata, entonces, de la abundancia que se abre en el lenguaje apenas las palabras ya no limitan con las cosas. Montaigne imaginaba un diálogo que Platón pudo haber escrito sobre las Indias, y anticipó esa conversación: "diríale yo a Platón..." Esa nostalgia que lo animaba, sostiene también otro discurso contrastante, de orden instrumental y más abierto al porvenir, el lenguaje utopista. Y si bien la prédica humanista del cortesano Gonzalo revela distancia irónica, es posible que Utopia de Thomas More forme parte de la alegoría que ensaya mientras recorre la vegetación de la Isla. Dados los contrastes 
de todo orden que favorece la ambivalencia del lenguaje, también es probable que en una última vuelta de tuerca, la misma pieza le pida a Gonzalo "no more". O sea, no más More."

Como observa John G. Demaray: "Before the final reconciliation that constitute a metaphoric rebirth, characters in the imperfect world of the play indulge themselves with social "imaginings". The essentially good counselor Gonzalo fancies an "antic" commonwealth of political and personal lassitude fortuitously supplied by a superabundant Nature". ${ }^{10}$

No menos fecunda es la fuente de motivos aducida para esta obra: More, Burton, pero también Ovidio y Virgilio. Incluso, la pieza podría responder, contrastante y no sin ánimo satírico, a la normatividad de algunos tratados cortesanos. Otra vez, la serie de oposiciones se convierte en el tema mismo de la biblioteca de Calibán.

Por lo demás, como recuerda Peter Hulme, incluso la experiencia colonial (y la lectura de la crítica neo-colonial de los años 70 que tendió a simplificar la visión de Calibán) incluye diversos discursos, y no solamente el predeterminado por el esquema de la dominación. Incluso, la servidumbre de Calibán corresponde al papel de proveedores de comida que las primeras crónicas de Indias atribuyen a los indígenas. Esta intermediación de los alimentos, que promueve una red comunicativa entre los exploradores y los nativos, sustenta también las interacciones simbólicas de mutua dependencia entre el amo y el siervo. Subraya, además, la importancia creciente de la comida y la bebida como ejes de la cotidianidad empírica y doméstica, económica y práctica. Esa densidad de textura y lenguaje irá a convertirse en un espacio social tan inmanente como simbólico, que por igual construye la esfera de lo cotidiano como los catálogos y taxonomías de una naturaleza fecunda y pródiga. Si la enumeración es el recurso retórico de la apropiación colonial, Calibán reapropia ese recurso para enumerar el blasón nativo. Nadie como él sabe los nombres y el lugar que suma los bienes pródigos: las frutas, los crustáceos y las aguas frescas que sólo él es capaz de proveer a Próspero, además de la mano de obra en el acarreo de la madera; y Próspero reconoce su dependencia a esos servicios. Pero Calibán expresa, además, el goce de la floresta mágica, donde el habitante paradisíaco refleja la transparencia de su intimidad y su mundo. Dice:

9 Evans, John X.: “Utopia on Prospero's island”, Moreana, 18, 1981, págs. 81-83.

10 Demaray, John G.: Shakespeare and the Spectacles of Strangeness, Duquesne University Press, 1998, pág. 117. 


\title{
JULIO ORTEGA
}

\begin{abstract}
Be not afeard. The isle is full of noises,
Sounds and sweet airs that give delight and hurt not.

Sometimes a thousand twangling instruments

Will hum about mine ears; and sometimes voices

That, if I then had waked after long sleep,

Will make me sleep again; and then, in dreaming,

The clouds methought would open and show riches

Ready to drop upon me, that, when I waked,

I cried to dream again.
\end{abstract}

$(3.2,148-156)$

Advierte a este respecto Barbara Baert: "the wild-man can complement the human condition, can actually improve it". ${ }^{11}$

El estudio de las posibles fuentes históricas de la obra, las crónicas e informes de navegación y exploración de la costa de Nueva Inglaterra y las islas del Caribe, que Shakespeare debió haber tenido en cuenta, demuestra que las plantas, frutos, pájaros y animales que menciona provienen tanto de Nueva Inglaterra como del Caribe. Pero elude explícitamente identificar la isla al mezclar unos y otros elementos; incluso, al eludir productos quizá más típicos, como es el caso de las palmeras, que identifican de inmediato a las Bermudas. No deja de ser ilustrativo el esfuerzo de Edward Everett Hale y Henry Cabot Lodge por demostrar que la isla de Cape Cod, en Nueva Inglaterra, es una fuente más verosímil de lo que ellos llamaron "la isla de Próspero". ${ }^{2}$

No es menos ilustrativo que hoy la llamemos la isla de Calibán. Ya no es la misma isla porque no se trata de las mismas lecturas. Pero tampoco se trata de los mismos personajes. Calibán es nombrado como esclavo, deforme y sucio; es concebido como monstruo y hombre-monstruo; es también deshumanizado como pez, perro, lagarto, mono, tortuga...Su doble naturaleza (hombre natural/noble salvaje) lo convierte en una figura de la crisis, esto es, en un nuevo sujeto cultural americano, que pone en entredicho el repertorio de las representaciones, el lenguaje de las definiciones y el sistema de las clasificaciones. Como las palmas que vio Colón, que se salían del campo de la mirada y exigían un habla metafórica para ser descritas; Calibán, como su mismo nombre, es un anagrama: una figura incongruen-

11 Baert, Barbara: "Caliban as Wild-Man, An Iconographic Approach," en Lie, Nadia, y d'Haen, Theo: Constellation Caliban, Figurations of a Character, Textxet 10, Amsterdan-Atlanta, 1997.

12 Hale, Edward Everett: Prospero's Island. With an introduction by Henry Cabot Lodge, dramatic Museum of Columbia University, New York, 1919. Series Discussions of the Drama. 
te, un principio de contradicción. No menos revelador es el hecho de que en la crítica haya dejado de ser un monstruo (trágico y cómico a la vez) para humanizarse en cada lectura, hasta hacerse el más humano de los personajes, el más histórico y veraz. ${ }^{13}$

David Norbrook señala muy bien el campo de fuerzas de este proceso significativo: "The play is not overtly oppositional or sensationally 'subversive'; but it subjects traditional institutions to a systematic, critical questioning. The play does not consider language and power as timeless absolutes; rather that counterpoising an inmediated, presocial nature to a deterministically conceived language, it is concerned with language in specific social contexts, with the effect of political structures on linguistic possibilities. All of the play's utopian ideals, not excepting Ariel's, come up for ironic scrutiny in the course of the play, precisely because they tend to an idealism that refuses to recognize the material constrains of existing structures of power and discourse. But that awareness need not imply a pessimistic determinism. A skeptical relativism about claims to an unproblematic 'human nature' is played against a searching, universalizing quest for a more general notion of humanity". ${ }^{14}$

Calibán termina humanizando a los hijos del discurso, a los herederos de la larga tradición mimética y retórica europea. Su lenguaje reciente, su humanidad temprana, ponen en crisis los modelos de nombrar y representar. Después de él, el lenguaje ya no será el mismo. Porque al modo de un espejo inverso, devolverá el rostro del que lo nombra: Calibán es ya un proyecto de diálogo, de oposiciones y articulaciones, de diferencias y conflictos. Por ello mismo, más que el producto legible del discurso, Calibán sólo podía ser el primer hijo de la nueva historia, una historia hecha en las interpretaciones.

Esas interpretaciones son las que construyen la isla de Calibán, el espacio del nuevo lenguaje americano, como una actualidad de la abundancia. Aprender a hablar la lengua del poder colonial puede, en efecto, confirmar el orden de la nueva normatividad y hacer del sujeto colonizado un reproductor de ese poder. Pero el exceso de la abundancia natural es también la matriz de un discurso que excede al archivo normativo, aquel

13 Bartra llama a Calibán "el primer hombre moderno". Bartra, Roger: El salvaje en el espejo, ERA y UNAM, México, 1992, págs. 162-164.

14 Norbrook, David: "'What cares these roares for the name of king?': Language and Utopia in The Tempest", R.S. White, ed. The Tempest, St. Martin Press, Contemporary Critical Essays, New York, 1999, págs. 167-190. 
que reproduce su control de lo que nombra y clasifica. La abundancia es la fisura del mundo en el lenguaje, la potencialidad creativa de un espacio aún sin discurso, prefigurado en la fuerza de los objetos que son el alfabeto del asombro - un asombro que se mueve de lo legendario a lo empírico. El poder colonial es un mapa en crecimiento, la cartografía de todos los espacios, incluso los que vacía. Administrar la abundancia, efectiva o potencial, incrementa el poder burocrático, tanto como dinamiza las instituciones de la banca en Flandes y en Italia. En las laboriosas encuestas que la administración española envió a las autoridades de Indias, varias de las preguntas son sobre el crecimiento de las plantas, las nativas y las introducidas por España, sobre sus mezclas y multiplicación. ${ }^{15}$ Pero hasta la isla de la Bermuda es representada como espacio de carencia, por su tierra árida e inhóspita, al menos en uno de los testimonios (el de W. Strachy, 1610) del naufragio de Sir Thomas Gates, el gobernador vuelto nativo feliz. Dado que se trata de un espacio privilegiado de la interpretación, no han de extrañar las representaciones contrarias de la isla: La Bermuda es llamada así por su descubridor, Juan de Bermúdez, según la crónica de Pedro Mártir; pero luego es conocida como "Las islas del Diablo," según otros viajeros desafortunados. Este proceso culmina en la isla encantada por su dulce aire musical, donde Ariel y Calibán son siervos que no ignoran el gusto de la libertad. The Tempest es una mascarada que escenifica su propia lectura plural. Es, se diría, una larga cita del Caribe como tropo y topos transatlántico.

No sorprende que en dos instancias críticas de la historia moderna latinoamericana la Isla de Próspero y Calibán haya sido representada como espacio de virtualidad. La primera es Ariel (1900) de José Enrique Rodó, un ensayo que asume el cruce de caminos del fin de siglo para, entre la tradición idealista y la tentación positivista, sugerir que Calibán es el símbolo del materialismo triunfal (representado por Estados Unidos) y Ariel el símbolo de la espiritualidad amenazada (representada por América Latina). Gordon Brotherston arguye que esa atribución es más producto de la interpretación del libro, gestada por el momento histórico crítico, que efectiva intención de Rodó, menos categórico y sistemático. ${ }^{16}$ En todo caso, bajo "el numen" de Ariel, este ensayo parte de la obra de Shakespeare, de su lec-

15 Cline, Howard F.: "The Relaciones geográficas of the Spanish Indies, 1577-1586," The Hispanic American Historical Review, vol. XLIV, núm. 3, August 1964, págs. 341-374.

16 Rodó, José Enrique: Ariel. Edited with an introduction and notes by Gordon Brotherston. Cambridge University Press, Cambridge, 1967. 
ción moral: es una convocación al futuro, a los más jóvenes, para defender y proseguir el desarrollo espiritual e intelectual frente al triunfo de las fuerzas materialistas. ${ }^{17}$ En cambio, en su debatido Calibán, Apuntes sobre la cultura de Nuestra América (1973) Roberto Fernández Retamar propuso que Ariel era el intelectual de la isla que podía aliarse con el rebelde Calibán en contra del poderoso e imperial Próspero. En esta relectura política de la escena colonial, Retamar construye un manifiesto revolucionario desde dentro de la Revolución Cubana, un discurso de oposición que unos, como Edward Said, han llamado de "resistencia" y otros, como Gayatri Spivack, han asociado a la crítica postcolonial. También gestado por la polémica y la convicción ideológicas, este manifiesto es una reescritura de la escena del lenguaje apropiado por Calibán para maldecir, en este caso para contradecir. No menos tributario de su momento, Retamar imagina en la pragmática discursiva de su Isla al Che Guevara dirimiendo la oposición Ariel/Calibán con su prédica apostólica y a nombre de las sumas de la revuelta futura. ${ }^{18}$

Ya Renan había previsto en su Caliban (1878) la historia de Ariel y Calibán como revolucionarios que sustituyen a Próspero sólo para terminar repitiéndolo. Al final, destruida su revolución, Ariel lamenta ante Calibán que el pueblo ya no crea en ellos, en su poder mágico: "El pueblo es positivista", repite. Esto es, el pueblo ha cambiado de discurso y se debe a una nueva interpretación. Más poderosa y persuasiva es la versión poética de Aimé Césaire, que en su Otra tempestad responde a Shakespeare desde la perspectiva de las Antillas y la práctica anticolonial.

En conclusión, más que a maldecir, Calibán ha aprendido, en verdad, a enumerar el bien gratuito y fecundo de su isla. Su acción de recobrarla no está en la cómica rebelión contra Próspero, ni en su asimilación al sistema colonial. Está en el hecho de nombrarla y enumerarla: su acto de habla es un hecho de vida, una nueva historia. Ha aprendido el lenguaje que lo sanciona, y que lo condena a maldecir (doble maldición, que pasa por vacía ganancia); pero es gracias al lenguaje que puede hacerse cargo de su pro-

17 Véase van Delden, Maarten: "The Survival of the Prettiest. Transmutations of Darwin in Rodó's Ariel," en Lie y d'Haen: Constellation..., págs. 145-161.

18 Estudia el impacto de este ensayo Nadia Lie: "Countering Caliban. Roberto Fernández Retamar and the Postocolonial Debate," en Lie y d'Haen: Constellation..., págs. 245-270. Ver también la discusión que desde la experiencia Afro-Americana se plantea en Baker Jr., Houston A.: "Caliban's Triple Play", en Gates, Jr., Henry Louis (ed.): Race, Writing, and Difference, The University of Chicago Press, Chicago, 1985, págs. 381-395; este ensayo se propone exceder el dualismo de la pieza entre Próspero y Calibán. 
pia embajada. Los nombres le devuelven una isla de la abundancia. No sabe qué hacer con ese poder incierto, todavía, pero aprender a hablar le ha enseñado que el mundo tiene el valor de sus nombres. Y que en el lenguaje se decide el poder de nombrar, de transformar, de recobrar.

El primer americano carece de lengua propia, pues no sabemos si hablaba alguna; tal vez aprendió no sólo una lengua sino el acto mismo de hablar. En ese caso, sería el primer personaje moderno nacido directamente en el lenguaje. No tiene otra memoria que el alfabeto natural que es capaz de articular como el lenguaje de un mundo hecho para el porvenir. De la abundancia natural, de la carencia de la libertad, Calibán nos lleva a la virtualidad, a ese espacio donde será tocado por la gracia del discurso europeo, que ya es el suyo, desde este lado americano del habla. Su habla aprendida es su primera ganancia de humanidad. En verdad, Calibán es el filósofo autodidacta caribeño: el nativo que descubre las cosas a partir de sus nombres.

Muchas otras criaturas de la diferencia americana se deben, así mismo, al repertorio fronterizo de la imaginación europea. Pero si resultan más bien fantasmas del relato de lo desconocido (fronteras europeas de ver y representar); son, en cambio, hijos efectivos de lo americano reconocido (sumas de habitar, comer, beber). Ese nuevo relato, a su turno, dará cuenta también de la violencia, el hambre y la miseria que erosionan la vida indígena. Sólo que su saber crítico posee la memoria de los bienes propios. El del uso del lenguaje es ya un bien común, interiorizado como la libertad misma de estas criaturas hechas en la licencia gramatical americana. Aprender a hablar será hacerlo en dos o más lenguas, las de la memoria étnica y la del futuro colonial: la lengua europea es el espacio del habla dominante pero su cartografía implicará un traslado continuo, un entramado de traducciones fluidas. Las lenguas nativas, hasta por el hecho de ser aglutinantes, asimilan el español, o al menos lo contaminan; y entienden pronto que el español es también un espacio de negociación.

Calibán aprende a hablar no sólo para maldecir sino para poner a trabajar a las palabras como instrumentos con que rehacer su doble herencia cultural, contra la violencia y a favor del bien común. Aun si lo vemos discurrir disminuido por la comedia, su figura es producto de las sumas europeas y americanas en el asombro y la promesa del Nuevo Mundo. Si Colón llegó a comparar el habla de los habitantes de una de las islas caribeñas con el ladrido de los perros; si algunos comentaristas creyeron que las lenguas indígenas tenían sonidos horrendos porque imitaban a los pájaros de las 
selvas; y si, en fin, incluso tratadistas del siglo XVIII todavía creían que las lenguas americanas carecían de gramática; Shakespeare, inspirado por Montaigne, forjó en Calibán un emblema más complejo y ambiguo: una criatura de la lengua colonial que empieza a hablar como si ese lenguaje pudiese ser la recuperación de su propio mundo. ${ }^{19}$

La lengua será la forma histórica del moderno sujeto americano, capaz de rehacerse en las sumas y disputas de un habla mutua, en ese verdadero nuevo mundo.

19 De Certeau, Michel: Heterologies, Discourse on the Other, University of Minnesota Press, Minneapolis, 1986; propone que el ensayo de Montaigne se desarrolla como una estrategia de secuencias discursivas que sostienen la palabra misma del caníbal, del otro. " 'Of Cannibals' is inscribed within this heterological tradition, in which the discourse about the other is a means of constructing a discourse authorized by the other", pág. 68. Esta estrategia implica "the circularity between the production of the Other and the production of the text". Esas tres fases corresponden al relato de viaje, al testimonio de la sociedad salvaje y, por fin, al retorno del salvaje mismo, que "retorna en el texto", págs. 69-70. 